\title{
Application study of the Tunnel Seismic Prediction method in Qiyueshan tunnel
}

\author{
Wei $L u^{1, a}$, Jing $W u^{1, b}$, Shucai $\mathrm{Li}^{1, \mathrm{c}}$, Zhenhao $X \mathrm{u}^{1, \mathrm{~d}^{*}}$, Liping $\mathrm{Li}^{1, \mathrm{e}}$, \\ Yanhuan Zhang ${ }^{1, f}$, Lun Zhou ${ }^{1, g}$ \\ ${ }^{1}$ Geotechnical and Structural Engineering Research Center, Shandong University, Ji'nan 250061, \\ Shandong, China \\ axqluwei@126.com, bwujing9516@163.com, ${ }^{\mathrm{c}}$ lishucai@sdu.edu.cn, ${ }^{\mathrm{d}, *}$ zhenhao_xu@sdu.edu.cn, \\ eyuliyangfan@163.com, 'rhangyanhuanlei@163.com, ${ }^{9} 18769788330 @ 163 . c o m$
}

Keywords: Tunnel Seismic Prediction method, QiYueshan tunnel, advanced geological prediction. Abstract. For deep tunnels, their engineering geological and hydro-geological conditions are highly changeable and complex. Rough construction often triggers or produces accidents, such as water inrush, mud inrush, landslides etc. For informational dynamic design and construction of tunnels, it is of vital importance to carry out advanced geological Prediction. Based on the engineering background of QiYueshan tunnel, a high risk karst tunnel in Livan expressway, combined with seismic propagation theory and TSP geological prediction practices, reflection characteristic of seismic wave for typical geology disaster in karst tunnel is studied. The important results of guiding tunnel construction are concluded. Application effect of prediction techniques is discussed. The scientificity and reliability of Prediction techniques are verified by comparing the prediction results with the practical projects.

\section{Introduction}

In recent years, the number of tunnels in road network has increased dramatically with the rapid development of expressway in our country [1]. In the process of tunnel construction, because geological conditions in front of the heading face are unknown, there will be a lot of geological problems, such as karst, fault fracture zone, water burst etc. If the problems are mishandled, the geological disasters such as landslides, water, mud inrush etc. will happen, which will endanger the personal and property safety [2-3]. The excavation depth of tunnel section increases with the rise of expressway. The requirements of mastering tunnel geological data are also increasing. But surface geological information is difficult to truly reflect geological conditions of the tunnel, so the prediction of geological conditions in front of the working face is very important to tunnel construction safety and construction organization design [4-6]. And it is also a key consideration and resolved problem in tunnel construction. Reliable, efficient and economical preprocessing scheme is worked out by adopting a variety of geological prediction technology, which is necessary to the design and construction of tunnel.

There are many geological prediction methods [7-9]. According to the mode of action for rock, they can be divided into destructive method and non-destructive method. They also can be divided into two prediction ways, i.e., long-distance prediction and short-distance prediction based on the prediction distance. Tunnel Seismic Prediction (TSP) method is one of the main methods of non-destructive and long-distance geological prediction during construction. Its prediction system has the advantages of both non-destructive method and long-distance prediction way. It has become an indispensable advanced geological prediction method and has been widely used in tunnel construction [10]. TSP method has achieved satisfactory results in domestic and overseas highway tunnels.

In the present study, the basic principle and method of TSP is introduced and studied. Reflection characteristic of seismic wave for typical geology disaster in karst tunnel is researched based on the engineering background of Livan expressway QiYueshan tunnel. The important results of guiding tunnel construction are concluded. Application effect of prediction techniques is discussed. The feasibility and accuracy of TSP technology is proved through engineering practice. 


\section{The Tunnel Seismic Prediction}

The basic principle of TSP seismic wave method advanced geological prediction is as follows, firstly, the holes are drilled in the tunnel sidewall. Then, the TSP equipment is stimulated by putting small doses of explosives into the holes. The signal generated by stimulation propagates along the tunnel in the form of spherical wave. Seismic waves propagate at different speeds in the different rock strata. Part of the signal penetrates through the interface. And part of the signal is reflected at its interface, which is received by the high precision receiver mounted on the sidewall. The signal is analyzed and disposed by TSP203 computer software. The geological structure in front of the heading face and physical mechanics parameters of surrounding rock are concluded and explained. According to the conjectural geometry, spatial relationships between geological interface and tunnel, the conditions of rock mass and groundwater in front of the heading face are judged.

The specific usage of TSP in the tunnel is as follows, when data acquisition is taken by microcomputer. 24 boreholes are drilled at regular intervals in the tunnel sidewall. And two detector holes are drilled on both sides of the wall. Putting the receiver and detector into the drive pipes, and each gun is stimulated in order. Then the seismic waves are generated, which propagate in the tunnel wall rocks (Fig. 1).

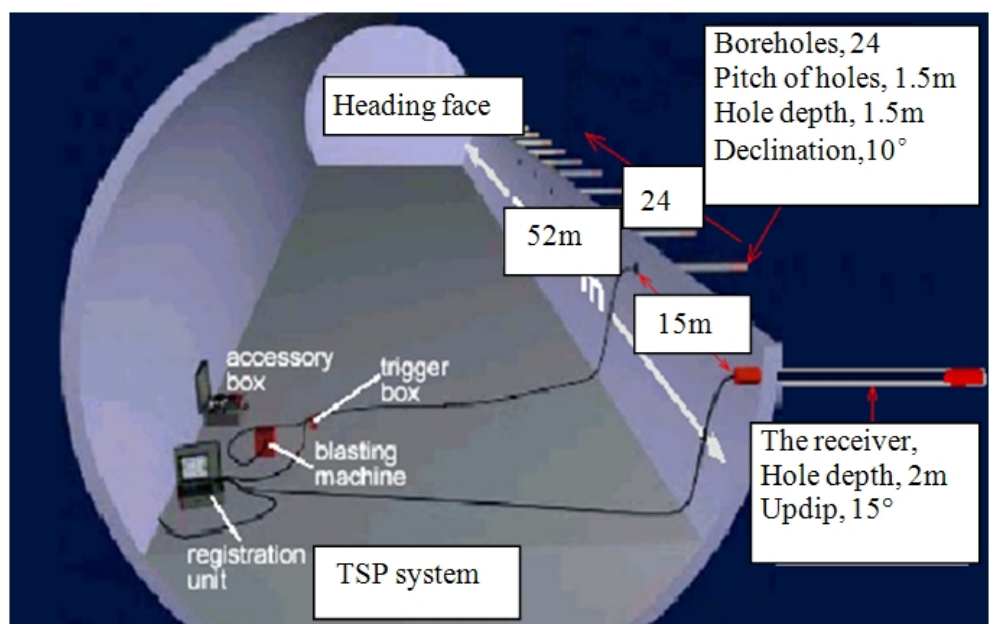

Fig. 1 The detection schematic diagram of TSP forecasting system

TSP data collected is disposed by TSP win software. The time section, depth migrated section, reflective layer extraction of $\mathrm{P}$ wave, $\mathrm{SH}$ wave, $\mathrm{SV}$ wave and petrophysical parameters are obtained. During the interpretation of results, the rock formations are divided mainly depend on P-wave data. Geological phenomena are explained by combining with transverse wave data. And following these guidelines,

(1) Hard rock is indicated by regular reflection amplitude. Soft rock is indicated by negative reflection amplitude.

(2) If the reflection of S-wave stronger than the P-wave, then the rock is full of water.

(3) Whether Vp / Vs increases or $\delta$ increases suddenly, it often caused by the presence of the fluid.

(4) If $\mathrm{Vp}$ decreases, the cracks and porosity of rock are indicated increase.

\section{The engineering background of Livan expressway Qiyueshan tunnel}

Qiyueshan tunnel is one of the dominant engineering in Livan expressway, which is located in Lichuan City, Hubei Province. The length of left tunnel is $3380 \mathrm{~m}$, and the right tunnel is $3282 \mathrm{~m}$. The tunnels are designed for crossing Qiyueshan. The underlying bedrocks are Permian limestone, siliceous limestone, shale, coal seams and Triassic limestone, and paper shale is existed in local area. Qiyueshan anticline is passed through by the tunnel. Both wings of the anticline are asymmetrical. The lithology is mainly dominated by limestone. Shale and coal seam are existed in local area. The emergence stratum 
of anticlinal core is Changxing thick-bedded limestone, and both wings are contacted by fault in the core of the anticline. Therefore, the tunnel belongs to karst area.

Two faults are developed in tunnel zone, and their performance in tunnel is narrow. They are perpendicular to the routine. Karst is mainly developed in the fault zone, and large karst cave may be existed. There are three karst groundwater systems in tunnel zone. Xiangshui hole underground river system is the largest karst underground river system in the region, which is located in the west side of Qiyueshan anticline. Its length of north-south is about $30 \mathrm{~km}$, and the width is about $4 \mathrm{~km}$. In addition, the elevation between Xiangshui hole underground river and the tunnel is equivalent in tunnel cross area, so the risk of great geological disasters is greatly elevated.

\section{The engineering application}

The advanced geological prediction for left hole in Livan expressway Qiyueshan tunnel is carried out by using TSP203. The data is collected by adopting TSP203plus instrument. 21 guns are stimulated in this TSP prediction, and the pitch of holes is $1.5 \mathrm{~m}$. The receiver is placed on the left of the tunnel wall. It receives signals from the tunnel face direction. The stake mark of working face is ZK20 + 310, and the stake mark of sensor is ZK20 +226 . Acquisition parameters are as follows, sample rate $62.5 \mu \mathrm{s}$, record length $7218, \mathrm{XYZ}$ three-component receive. The detection range of the import is from ZK20 + 310 to $\mathrm{ZK} 20+440$, and the total distance is $130 \mathrm{~m}$.

The seismic signal received is processed by using TSP win software. The wave velocity of rock mass and petrophysical parameters in front of the working face are obtained. Fig. 2 shows the depth migration of P-wave. Fig. 3 shows the results of 2D and the petrophysical properties.

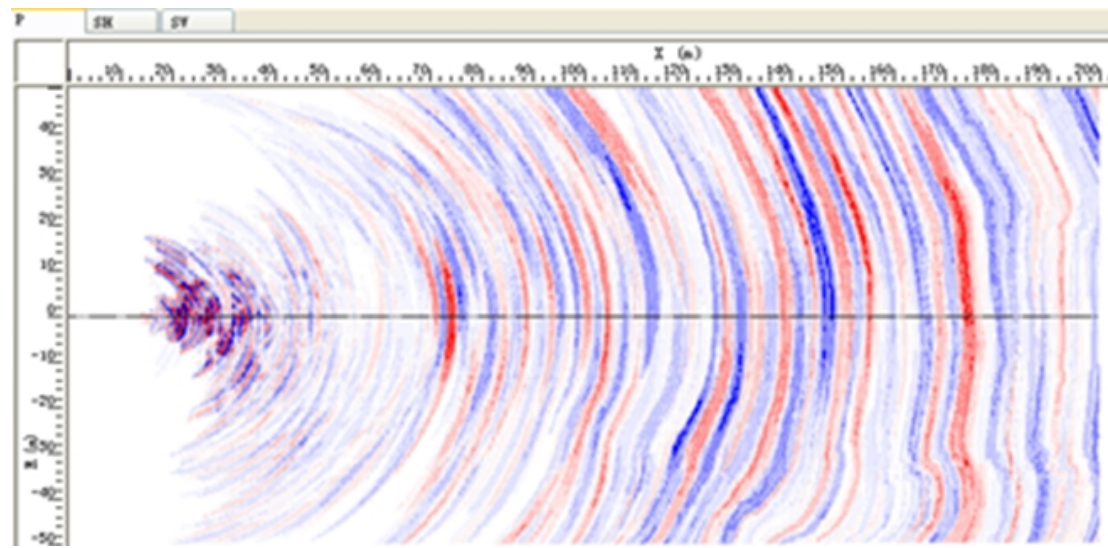

Fig. 2 The depth migration of P-wave

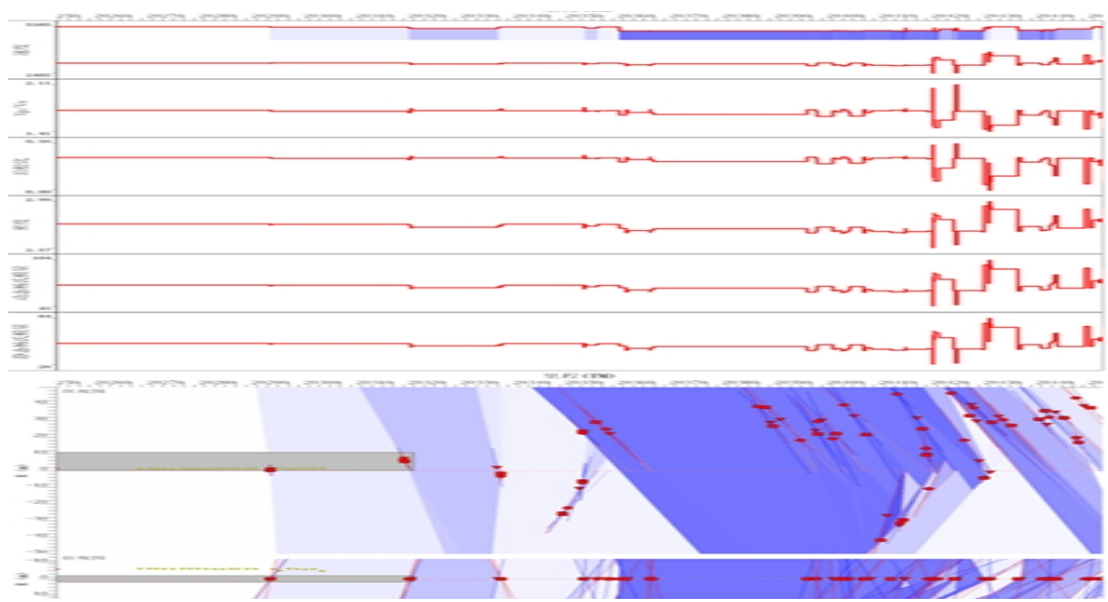

Fig. 3 The results of 2D and petrophysical properties

The following conclusions can be obtained from Figs 2-3,

ZK20+310 ZK20+362, the length is $52 \mathrm{~m}$. The detailed explanation for detection results is as follows. The strength of this section surrounding rock is similar to excavation section, but its integrity is slightly less 
than excavation section. The development of joint fissure is average. Corrosion fissure water and folder mud structures are existed in local area. The integrity of surrounding rock for ZK20+320 ZK20+332 section, ZK20+346 ZK20+362 section is not good enough, and its fluid content is much higher, so the corrosion cracks and holes may be existed. It is suggested that advance drilling should be done before excavation, meanwhile, support system and waterproofing and drainage measures should be reinforced. The construction cannot be done until the situation is ascertained.

ZK20+362 ZK20+402, the length is $40 \mathrm{~m}$. The detailed explanation for detection results is as follows. Compared with the previous section surrounding rock, the overall integrity of this section surrounding rock is better, and the fluid is existed in local area. The integrity and strength of surrounding rock for ZK20+362 ZK20+ 388 section are much better, and the growth of corrosion cracks is weak. The seismic waves signal for ZK20+388 ZK20+402 section is abnormal. Regular and negative reflection is alternated, meanwhile, $\mathrm{Vp} / \mathrm{Vs}$ increases, and the variation of Poisson's ratio, density is abnormal. It is inferred that the strength of surrounding rock is strong and weak alternately, and the growth of corrosion cracks is relatively developed, thus, the possibility of karst cave existence is much higher. It is recommended that advance drilling and advance blast hole must be applied in this section before excavation. The construction cannot be done until the situation is ascertained, reminding attention to construction safety.

$\mathrm{ZK} 20+402 \sim \mathrm{ZK} 20+440$, the length is $38 \mathrm{~m}$. The detailed explanation for detection results is as follows. Compared with the previous section surrounding rock, the integrity of this section surrounding rock is poorer, and the fluid content is higher, which is based on the results of TSP image display. So a large karst cave may be existed in this section. Regular and negative reflection for ZK20+412 ZK20+440 section is alternated, meanwhile, $\mathrm{Vp} / \mathrm{Vs}$ increases, and the variation of Poisson's ratio, density is abnormal. It is inferred that large karst cave and water flowing fractured may be existed in this area. In addition, water content is much higher. It is suggested that advance drilling and advance blast hole must be applied in this section before excavation. The purpose is to prevent water inrush and mud inrush from happening.

Overall, comprehensive analysis is achieved on the basis of TSP detection results and geological data analysis. The general condition of prediction section is similar to working face, i.e., the weak weathering argillaceous limestone. Within the scope of ZK20+32 ZK20+332 section, ZK20+346 ZK20+362 section, ZK20+388 ZK20+402 section, ZK20+412 ZK20+440 section, the development condition of surrounding rock fracture is average level. The strength and integrity are relatively poor, and the karst fissure water content is high. Thus, the possibility of karst cave existence is much bigger. The advance drilling and advance blast hole must be applied before excavation. The footage should be controlled during the construction. Waterproofing and drainage measures should be well done. The purpose is to prevent water inrush and mud inrush from happening, reminding attention to construction safety.

During the subsequent tunnel excavation, the working face of ZK20 + 414 seeps mud, and a karst cave is found in the vicinity of the working face. The results are shown in Fig. 4. The analysis results coincides with actual excavation results, therefore, the accuracy of detection is proved.

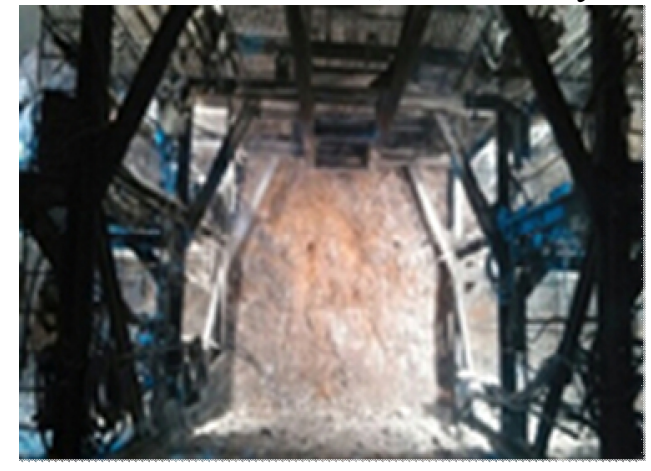

(a)The working face

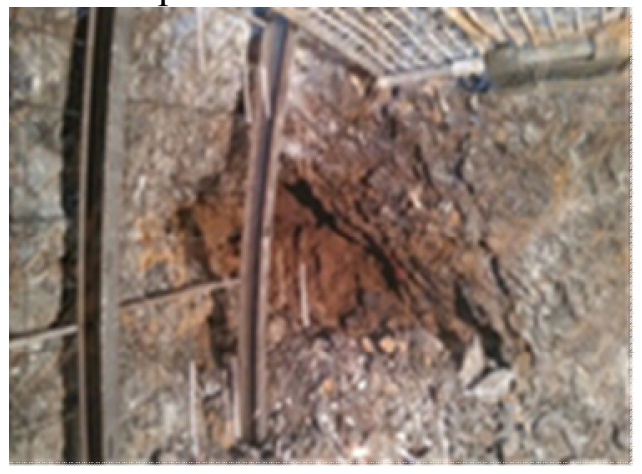

(b)The karst cave

Fig. 4 The excavation results 


\section{Summary}

The advanced detection for Qiyueshan tunnel is achieved by using TSP technology. The variation of geological conditions in front of the working face is ascertained and mastered in advance. The corresponding technical measures are taken timely. The safety of the tunnel construction is ensured, and the following conclusions are obtained.

(1) TSP method can accurately detect adverse geological interface in front of the working face, and it can also provide velocity, Poisson's ratio, rock integrity coefficient, Young's modulus and other parameters. In the process of actual excavation, the rock masses classification in front of the tunnel face can be generally predicted based on the parameters obtained and engineering geology-related contents, which provide a basis for tunnel excavation scheme.

(2)The advanced geological prediction of tunnel is a comprehensive work. According to the results of geological prediction, the range of unfavorable geologic bodies is pointed out. The purposeful and customized advance drilling of surrounding rock in front of the working face is carried out. Then the scope of fracture zone and aquifer structure can be further confirmed. It is laid a good foundation for the next grouting and advanced reinforcement.

(3) TSP technology reduces blindness and insecurity under construction. It greatly improves the accuracy and reliability of advanced prediction. That is to say, the construction period of tunnel is shortened, and accident incidence of tunnel is reduced. TSP technology provides strong protection for smooth construction of tunnels.

\section{References}

[1] Li S, Li S, Zhang Q, et al. FORECAST OF KARST-FRACTURED GROUNDWATER AND DEFECTIVE GEOLOGICAL CONDITIONS [J]. Chinese Journal of Rock Mechanics and Engineering, 2007, 2: 000.

[2] ZHANG Q, LI S, SUN K, et al. Analysis and Present State of Advanced Underground Space and Engineering, 2008, 4(4): 640-644.

[3] SUN K, LI S, ZHANG Q, et al. Application of the TSP geological forecast method of a mountain tunnel in a karst zone [J]. Journal of Shandong University (Engineering Science), 2008, 1: 019.

[4] ZHOU L, LIU T, LIU J, et al. Research on Application of TSP Detection Technology in Geological Forecast in Advance for Construction of Railway Tunnel [J]. Journal of Railway Engineering Society, 2008, 1: 007.

[5] Jin-wu Z O U Z H E, Lin W. The application of geological radar in advanced geological forecast of Changwuling tunnel [J]. Shanxi Architecture, 2008, 4: 211.

[6] LV Q, LUO X, Ren H. Application of Integrated Advance Geology Forecast Technology in a River-crossing Tunnel [J]. Tunnel Construction, 2009, 2: 011.

[7] Kang M A, Jin X U, ZHANG Z. Research on advanced prediction and forecast of Xuefeng Mountain Highway tunnel [J]. Rock and Soil Mechanics, 2009, 30(5): 1381-1386.

[8] Lin C N, Li L P, Han X R. Research on forecast method of tunnel water inrush in complex karst areas[J]. Chinese Journal of Rock Mechanics and Engineering, 2008, 27(7): 1469-1476.

[9] Ma H, Chen S, Tan X, et al. Advanced geological detection for tunneling in karst area[J]. Bridges, 2014, 10: 9780784412121.340.

[10] Guo J, Luo C. Application of Tunnel Seismic Image Approach to the Advanced Geological Prediction for Tunnel [J]. Journal of Multimedia, 2014, 9(7): 879-886. 